\section{POSSIBILIDADES DE ATUAÇÃO DO PROFESSOR DE EDUCAÇÃO FÍSICA NO PROCESSO DE APRENDIZAGEM DE ALUNOS COM DEFICIÊNCIA}

\author{
POSIBILIDADES DE ACTUACIÓN DEL PROFESOR DE EDUCACIÓN FÍSICA EN \\ EL PROCESO DE APRENDIZAJE DE LOS ALUMNOS CON DISCAPACIDAD
}

\author{
POSSIBILITIES FOR PHYSICAL EDUCATION TEACHERS' WORK IN THE \\ LEARNING PROCESS OF STUDENTS WITH DISABILITIES
}

\author{
José Milton Azevedo Andrade*, Ana Paula de Freitas ${ }^{\star \star}$
}

Palabras clave Inclusión Educacional.

Enseñanza. Educación Física. Discapacidad Física. Deficiencia Visual.

Keywords Mainstreaming (Education). Teaching. Physical Education. Physical disability. Vision Disorders.
Resumo: Objetiva-se, neste estudo, analisar os modos de agir do professor de Educação Física na inclusão de alunos com deficiência na escola regular. A pesquisa está ancorada nos pressupostos teórico-metodológicos da perspectiva histórico-cultural. A parte empírica foi realizada em duas escolas regulares da rede pública. As observações focalizaram duas professoras de Educação Física, durante as relações intersubjetivas com alunos com deficiência e seus pares. Para a construção dos dados recorreu-se a videogravação, para registrar as tramas vividas pelas professoras e alunos durante as aulas. A partir da análise microgenética, foi possível apontar indícios de que a função docente é preponderante na organização das possibilidades de participação, aprendizagem e desenvolvimento dos alunos com deficiência, desde que sejam oportunizadas estratégias que considerem as singularidades desses alunos.

Resumen: El objetivo, en este estudio, es analizar las formas de actuación del profesor de Educación Física en la inclusión de los estudiantes con discapacidad en las escuelas regulares. La investigación está anclada en los principios teóricos y metodológicos de la perspectiva histórico-cultural. La parte empírica se llevó a cabo en dos escuelas públicas regulares. Las observaciones se centraron en dos profesoras de Educación Física, durante sus relaciones intersubjetivas con estudiantes discapacitados y sus pares. Para la construcción de los datos, se utilizó el recurso de grabación de vídeo para registrar las situaciones experimentadas por las profesoras y los estudiantes durante las clases. A partir del análisis microgenético, fue posible señalar indicios de que la función docente es predominante en la organización de las posibilidades de participación, aprendizaje y desarrollo de los alumnos con discapacidad, siempre que sean ofrecidas estrategias que consideren las singularidades de esos estudiantes.

\footnotetext{
Abstract: This study aims to analyze how Physical Education teachers work to include students with disabilities in regular schools. The research is based on the theoretical and methodological assumptions of the cultural-historical perspective. The empirical part was conducted in two regular public schools. Observations focused on two Physical Education teachers during their intersubjective relations with students with disabilities and their peers. Video recordings were used for data collection and for recording the situations lived by teachers and students during classes. Through micro genetic analysis, evidence emerged that the teaching role is crucial in organizing opportunities for participation, learning, and development of students with disabilities, as long as they are offered strategies that take their unique characteristics in account.
}

* Centro Universitário da Fundação Educacional de Barretos. Barretos, SP, Brasil.

E-mail: zemilto@yahoo.com.br

** Universidade São Francisco. Itatiba, SP, Brasil.

E-mail: freitas.apde@gmail.com

Recebido em: 22-04-2016 Aprovado em: 17-08-2016 (c) (1) (8) Licence 


\section{INTRODUÇÃO}

A inclusão de alunos com deficiência na rede regular de ensino (BRASIL, 2008) tem trazido implicações significativas para o cotidiano escolar. Estudos indicam que 0 acesso à escola foi garantido por lei; todavia, o acesso ao conhecimento escolar ainda é um desafio (KASSAR, 2011; GAIO; DIAS, 2011; SILVA, 2015). As políticas de educação inclusiva não delimitam com clareza as ações estruturais e pedagógicas necessárias à efetivação da inclusão escolar e, desse modo, os alunos com deficiência estão alijados de um processo de ensino e de aprendizagem eficiente e de qualidade. Nesse contexto, realizou-se uma pesquisa de mestrado, com o intuito de compreender as possibilidades de aprendizagem de alunos com deficiência nas aulas de Educação Física da escola regular. O presente texto, recorte da referida pesquisa, focaliza o papel do professor dessa disciplina para a participação e a aprendizagem de alunos com deficiência. $O$ objetivo é analisar os modos de agir do professor de Educação Física na inclusão de alunos com deficiência na escola regular. Seabra Júnior (2006) focaliza a ação educativa do professor de Educação Física como fator que influencia o processo de inclusão de alunos com deficiência. Afirma que o professor é "[...] um elemento importante, muitas vezes decisivo, na construção e na efetivação do processo inclusivo" (SEABRA JÚNIOR, 2006, p. 98).

A pesquisa fundamenta-se nos pressupostos da teoria histórico-cultural (VIGOTSKI, 1995, 1997, 2000, 2009). Vigotski preocupou-se com a compreensão do desenvolvimento humano e, sem deixar de lado os aspectos biológicos que constituem o homem, atribuiu papel essencial aos fatores culturais. Para 0 autor, a constituição humana ocorre à medida que 0 homem vai se apropriando das práticas culturais, em situações sociais, necessariamente mediadas pelo outro e constituídas pela linguagem.

Nessa teoria, a mediação é compreendida como a relação que o homem estabelece com o mundo, de forma indireta e mediada: função para a qual os signos e os instrumentos são imprescindíveis. Os instrumentos são elementos interpostos entre o sujeito e o objeto de sua ação; ou seja, tornam-se mediadores da relação entre o indivíduo e o mundo social. Os signos atuam nas atividades de ordem psicológica, auxiliando na resolução das tarefas de lembrar, comparar e comunicar-se no meio social (VIGOTSKI, 1995). Os signos e os instrumentos ocupam papel fundamental no desenvolvimento e constituição dos sujeitos. Dainez e Deciete (2012) explicam que o homem produz e usa instrumentos e, nesse sentido, esses instrumentos, ao mesmo tempo, afetam e constituem o humano. Para as autoras (DAINEZ; DECIETE, 2012, p. 854), "[...] o técnico é semiótico e o semiótico é técnico". Assim, há relação intrínseca entre instrumentos e signos, na medida em que o instrumento (técnico, criado pelo homem), ao modificar a natureza, afeta e transforma o homem (significação).

Smolka (2004) explica que o signo é produzido a partir de condições concretas, resultado de relações sociais de produção. No contexto pedagógico, a participação deliberada do outro se torna fator fundamental para se pensar nas possibilidades de aprendizagem. Para Vigotski (2000), o conhecimento tem gênese nas relações sociais e ocorre no espaço da intersubjetividade. Tendo isso em vista, pensar no papel do professor para a elaboração do conhecimento significa compreender que é na dinâmica dos processos interpessoais que ocorre a possibilidade de aprendizagem dos conteúdos escolares. A relação entre sujeitos (por exemplo, alunos e professores) é mediada pela palavra, considerada, para Vigotski (2009), o signo por excelência. 
No que diz respeito à Educação Física Escolar, Seron, Rinaldi e Tuleski (2011) concebem que a teoria histórico-cultural pode contribuir para a melhoria das práticas pedagógicas. As autoras realizaram um estudo com 0 intuito de compreender como está ocorrendo a apropriação dos conceitos elaborados por Vigotski, em trabalhos científicos da área da Educação Física. Constataram que há poucas pesquisas que se orientam pela referida teoria e, quando isso ocorre, há falta de rigor epistemológico. Assim, investigar o papel do professor de Educação Física no processo de aprendizagem de alunos com deficiência, à luz da teoria histórico-cultural, torna-se relevante para contribuir com um exercício dialético que leve a reflexões sobre novas possibilidades educacionais para esses alunos.

O conceito de compensação, discutido por Vigotski $(1995,1997)$, é central no processo de desenvolvimento de pessoas com deficiência e se relaciona ao funcionamento psíquico, numa ideia que corresponde à plasticidade dos processos de desenvolvimento. Compreendendo que o desenvolvimento humano é dinâmico e passível de transformações, Vigotski considera que as interações estabelecidas no grupo social se tornam fundamentais no processo de compensação, que ocorre quando são oferecidos ao deficiente caminhos de aprendizagem marcados por práticas sociais significativas.

Ao problematizar a noção de compensação, Dainez (2014) aponta que o autor sustentava suas formulações com o princípio da natureza social do homem, qualificando o conceito com o termo social e, desse modo, marcando a função elementar do outro na constituição da pessoa com deficiência. Assim sendo, o princípio do desenvolvimento é o mesmo para todos os sujeitos, com ou sem deficiências.

Em relação a essa acepção, neste texto ressalta-se o papel intencional e planejado do professor, que pode viabilizar condições e buscar estratégias de aprendizagem para tornar o ensino significativo para todos os alunos. Souza e Smolka (2009) e Chicon, Mendes e Sá (2011) se dispuseram a investigar as práticas de inclusão no contexto das aulas de Educação Física da escola pública regular.

Souza e Smolka (2009) examinaram um fragmento de uma aula de Educação Física, focalizando a relação entre o professor e um aluno com sequelas de hidrocefalia. Constataram que o modo como o professor organizava e conduzia as atividades evidenciava a deficiência e o consequente fracasso do estudante na execução delas. No episódio analisado, o aluno deveria locomover-se, pulando e passando por um arco, até um ponto fixo determinado pelo professor. $\mathrm{O}$ aluno apresentou dificuldades, retorcendo-se devido a pouca flexibilidade e força para realizar o proposto. 0 professor percebe a ação, pede que o estudante interrompa a atividade na metade do percurso, e elogia a sua realização. No mesmo exercício, outro aluno, que não apresenta deficiência, percorre a mesma distância do estudante com deficiência, sem alcançar o ponto definido na atividade; então, o professor nota e adverte esse aluno. As autoras analisaram que, na cena apresentada, a maneira e o espaço que o aluno com deficiência vai ocupando no processo ensino-aprendizagem caracterizam-se como corpos marcados pelas deficiências.

Chicon, Mendes e Sá (2011) verificaram que práticas de ensino realizadas por uma professora de Educação Física que tem em sua turma dois alunos com deficiência, um com baixa visão e outro com síndrome de Down, podem levar os estudantes a reproduzirem condutas de segregação em relação aos colegas com deficiências. Isso ocorre quando a professora naturaliza a não participação desses alunos com deficiência nas atividades em 
grupo. Como ilustra o estudo, a professora não criava condições para que esses alunos fossem contemplados com os conteúdos de Educação Física junto a seus pares, pois a docente disponibilizava uma bola para manipularem em um espaço separado dos demais alunos da turma. E, quando os colegas se aproximavam para realizarem práticas em conjunto, eram censurados pela professora.

Esses estudos indicam que ainda há fragilidades no trabalho realizado pelo professor de Educação Física, em relação às práticas pedagógicas com alunos com deficiência. Assim, busca-se, neste texto, analisar os modos de agir do professor de Educação Física na inclusão de alunos com deficiência na escola regular.

\section{MÉTODO}

Esta pesquisa ${ }^{1}$ foi realizada em duas escolas (aqui denominadas escolas A e B) da rede estadual, situadas em dois municípios de pequeno porte do interior paulista, pertencentes à mesma regional de ensino. As escolas foram selecionadas em virtude de terem alunos com deficiência e de as professoras concordarem com a realização da pesquisa.

$\mathrm{Na}$ escola A, a professora observada é Jane ${ }^{2}$, com 26 anos, formada em Educação Física há seis anos. Tem especialização em Educação Especial, além de cursos de atualização voltados a essa temática. Ítalo, 13 anos, com deficiência física, é aluno da professora Jane e cursava $07^{\circ}$ ano do ensino fundamental. Sua deficiência é resultante de má-formação congênita, a Mielomeningocele, uma lesão na coluna cervical que compromete seus movimentos nos membros inferiores. Sua locomoção é lenta, realizada apenas com o auxílio de botas ortopédicas.

Na escola B, o estudo foi realizado com Marisa, 46 anos, que atua há 22 anos na educação básica. Concluiu a faculdade de Educação Física no fim da década de 1980. Formou-se também em Pedagogia e concluiu outros cursos de aperfeiçoamento. João, 16 anos, matriculado no $2^{\circ}$ ano do ensino médio, cego desde os dois anos de idade, devido a um tumor nos olhos (Retinoblastoma Bilateral), não utiliza bengala para guiar sua locomoção, o que o torna dependente do outro na ação de deslocamento.

Em ambas as escolas, as observações das aulas de Educação Física realizaramse semanalmente, durante o segundo semestre letivo de 2012. Em virtude de fatores como atividades culturais desenvolvidas pelas escolas com suspensão das aulas e ausência das professoras ou dos alunos com deficiência, foram observadas oito aulas ministradas pela professora Jane e seis aulas pela docente Marisa.

Em consonância à matriz teórica histórico-cultural, foi utilizado o recurso de videogravação para a construção de dados, permitindo se recorrer, quantas vezes necessárias, às ocorrências da dinâmica intersubjetiva escolar, em busca de explicações para os fenômenos observados no cotidiano escolar. Após as filmagens, os registros foram transcritos em ortografia regular, almejando realizar a análise microgenética dos dados. Para Góes (2000, p. 21), 0 "mais interessante da análise microgenética está numa forma de conhecer que é orientada para minúcias, detalhes e ocorrências residuais, como indícios, pistas, signos de aspectos relevantes de um processo em curso".

1 A pesquisa foi aprovada pelo Comitê de Ética em Pesquisa do Centro Infantil de Investigações Hematológicas Dr. Domingos Adhemar Boldrini. 2 Todos os nomes utilizados são fictícios a fim de preservar a identidade dos sujeitos. 
Portanto, os procedimentos metodológicos adotados para a realização deste estudo, que investiga os modos de ação das professoras de Educação Física para a aprendizagem e o desenvolvimento de alunos com deficiência, justificam-se pela característica do problema.

\section{RESULTADOS E DISCUSSÃO}

Com o propósito de caracterizar as ações pedagógicas das duas professoras no processo de inclusão de alunos com deficiência nas aulas de Educação Física, foram selecionados para este texto três episódios, decorrentes de duas aulas, uma da professora Jane e outra da professora Marisa. Nas demais aulas observadas, as ações das duas docentes apresentaram-se de modo similar, ou seja, buscando caminhos possíveis para que os alunos com deficiência, assim como os demais, participassem das atividades propostas.

A disciplina de Educação Física, no currículo escolar paulista (SÃO PAULO, 2010), é marcada pela sua especificidade prática, com atividades externas à sala de aula, e situações de ensino-aprendizagem desenvolvidas em sala de aula, momentos em que o trabalho com os conceitos científicos é mais valorizado. Considerando o exposto, as duas professoras trabalham conteúdos escolares de Educação Física em sala de aula, assim como as vivências do movimento na quadra esportiva. Em alguns momentos as situações colocadas foram mais dinâmicas, como deslocamentos que exigiram a velocidade de ambos os estudantes. Por outras vezes, atividades de baixa intensidade e pouca mobilidade, como exercícios de alongamento e manipulação de objetos. Desse modo, os dados foram organizados em dois eixos de análise: situação de aula teórica e situação de aula prática. Em cada eixo há episódios apresentados em turnos ${ }^{3}$ com o intuito de focalizar a dinâmica dialógica entre os sujeitos.

\subsection{Situação de aula teórica}

\section{Episódio 1:}

A professora Jane apresenta a modalidade esportiva handebol, como o novo conteúdo que irão trabalhar durante as próximas aulas. Ítalo e alguns alunos expressam conhecimento sobre a modalidade:

1. Profa.: Conforme conversamos na aula passada, hoje nós vamos começar com o handebol. Lembram?

2. Ítalo: Parece futebol, professora, mas joga com as mãos.

3. Leonardo: É, mas parece um pouco com basquete também. Eu já vi jogos, e eles batem a bola no chão para andar.

4. Ítalo: Mas no basquete faz cesta, e no handebol faz gol igual no futebol. (Sorri)

5. Ronaldo: Acho que já jogamos esse jogo, professora.

6. Turma: (Muitos alunos manifestam algum conhecimento sobre a modalidade)

7. Profa.: Ótimo, tudo que vocês falaram faz sentido com o jogo de handebol. Realmente ele parece com o futebol, não pelo gol, mas por conta da meta onde faz o ponto. E parece com o basquetebol também, pois precisa quicar bola para movimentar-se. Porém, o jogador pode dar três passos sem quicar a bola no chão.

8. Ítalo: (Atento à explicação) 
9. Jéssica: Como assim, professora?

10. Profa.: Assim: um, dois, três. (Faz o movimento com uma bola de handebol na mão)

11. Ítalo: (Observa a movimentação da professora)

12. Jéssica: Sim, então vamos jogar.

13. Profa.: Vamos sim, vamos para quadra, e lá vou explicar como vai ser o jogo. Podem ir, mas não façam barulho nos corredores. (Fica na porta da sala observando a movimentação dos alunos durante o percurso até a quadra)

14. Ítalo: (Espera a maioria sair, levanta e vai com o Leonardo para a quadra)

A professora inicia a atividade com um diálogo com a turma sobre o handebol, criando espaço para que os alunos relatem suas experiências com a referida modalidade. Ítalo e seus colegas aproveitam a oportunidade propiciada pela professora e revelam seus conhecimentos cotidianos sobre o esporte (turnos 1 a 6). Conforme abordou Vigotski (2009), há sempre uma história prévia oriunda da prática social nas situações de aprendizagem com as quais 0 aluno se depara na escola. Nessa cena, quando Jane anuncia o conteúdo e oportuniza o espaço para que os alunos se manifestem oralmente, visualiza-se o papel intencional da professora, que convoca os alunos para o diálogo e, por meio da palavra, cria oportunidades de participação de todos os alunos.

No início da aula, Ítalo revela seus conceitos cotidianos, que, segundo Vigotski (2009), são elaborações decorrentes das suas experiências, valores culturais apenas possíveis de serem apropriados pelo social. Outros significados do handebol, bem como os conceitos mais complexos que permeiam sua cultura de movimento, devem ser possibilitados pela escola. São processados a partir da sua articulação com o conhecimento que o sujeito já domina (cotidianos), e passam a ser categorizados e ampliados de forma sistematizada por meio das práticas de ensino do professor.

$\mathrm{Na}$ escola, o conhecimento é orientado e sistematizado numa lógica organizada e deliberada pelo professor. Assim a professora de Ítalo faz, ao divulgar aos alunos a cultura de movimento que irão estudar, ouvindo e valorizando o que eles demonstram já conhecer. E, depois, explica as características da modalidade, correlacionando-as aos exemplos indicados pelos alunos, diferenciando-os quando necessário. Nos turnos 7 e 10, com a mediação de palavras e gestos, a professora explica sobre o jogo. A dúvida da aluna Jéssica é respondida com o movimento de como se joga. Nota-se que os sentidos para o conhecimento escolar que está em curso, o handebol, vão sendo construídos na dinâmica dialógica. Nesse sentido, a ação educativa do professor configurou-se como elemento fundamental para possibilitar a participação de todos os alunos nas situações de aprendizagem (SEABRA JÚNIOR, 2006).

\subsection{Situação de aula prática}

\section{Episódio 2:}

Todos chegam à quadra, a professora Jane solicita aos alunos que se dirijam ao centro e façam um círculo. Quatro alunos vão para a arquibancada da quadra. Jane os chama para participarem, eles acenam que não. Ítalo chega e posicionase no local que a professora solicitou. Ela pega uma bola de handebol e se junta à turma, agora com trinta alunos, e começa a explicação da atividade: 
1. Profa.: Bom, a bola de handebol, essa aqui ó! Preste atenção, ela tem alguns tamanhos diferentes. Essa aqui é a H1L, tem a H2L e a H3L. Então nós vamos crescendo de acordo com a categoria que vocês estão participando. Agora a categoria de vocês é a H1L, a bola encaixa fácil na mão, é melhor para manusear.

2. Ítalo: (Atento, observa a explicação dos diferentes tamanhos de bola pela professora)

3. Profa.: O jogo que nós vamos fazer, agora, vai precisar de algumas habilidades do handebol. Essas habilidades são o passe e alguma coisa do arremesso, porque vocês vão ter um objetivo no movimento de vocês. Então, começa com duas pessoas sendo os queimadores, esses dois vão trocando passes, não podem andar com a bola na mão. Eu só posso me movimentar quando eu estou sem a bola. Então, se está eu e o Leonardo, quando eu passo a bola, eu me movimento; recebi a bola de volta, não me movimento mais. (Demonstra a movimentação e manipulação da bola com o Leonardo)

4. Ítalo: (Continua atento à explicação e demonstração da professora)

5. Turma: (Os alunos prestam atenção à professora, depois conversam discretamente com o colega ao lado sobre a atividade apresentada)

6. Profa.: O objetivo é trocar passes até queimar alguém. Queimando o colega, esse vai integrar o grupo. Assim, vão estar em três e passar a bola entre eles até queimar o próximo. Além de queimar todos, preocupem-se em trocar passe para conquistar o alvo. É mais fácil acertar a Jéssica de onde estou, ou passar a bola para o Ítalo, que está próximo dela, para ele queimar? (Lança a bola para Ítalo, que recebe e encosta a bola em Jéssica)

7. Ítalo: É melhor passar a bola mesmo. (Sorrindo, participa da demonstração da troca de passes com professora)

8. Profa.: Então é essas coisas que vocês vão estar percebendo, e já trabalhando em grupo. Alguém não entendeu?

9. Jéssica: (Levanta a mão)

10. Profa.: Não entendeu?

11. Jéssica: (Acena com a cabeça sinalizando que não)

12. Ítalo: (Observa Jéssica e a professora)

13. Profa.: Duas pessoas começam, eu e você trocando bola, o espaço é a quadra toda que está valendo, nós vamos tentar queimar alguém, eles vão fugir da gente, e nós vamos atrás deles passando bola. Quando conseguirmos queimar alguém, essa pessoa vem para nosso grupo, que continua até conseguirmos queimar todos.

14. İ́alo: Enquanto não queimar ninguém, ficam apenas os dois passando a bola?

15. Leonardo: Por que não começa só com uma pessoa?

16. Profa.: Olha só, prestem atenção, se começarmos com um, qual é a regra principal do jogo? É não andar com a posse da bola, se começar com uma pessoa, como ela vai fazer para alcançar outra pessoa com a bola? Por isso inicia com duas pessoas, assim, quando uma passa a bola, a outra movimenta para ficar próximo do colega que vamos queimar.

17. Ítalo: (Fala algo para Leonardo, ininteligível à gravação)

18. Turma: (Alunos conversam entre si sobre a explicação da professora)

19. Profa.: Então vamos lá, quem são os dois que vão começar? (Afasta-se para lateral da quadra) 
20. Ítalo: (Permanece no centro da quadra ao lado de Leonardo)

21. Turma: (A maioria dos alunos sai em direção à professora, prontificando-se para iniciar o jogo)

22. Profa.: Pessoal, por favor, cuidado com a força quando passarem a bola para 0 colega e quando tentarem queimar alguém. Eu também estou no jogo! (Alguns alunos comemoram 0 anúncio da sua participação)

23. 0 jogo tem início com a dupla Laís e Jeferson. Ítalo posiciona-se distante da dupla de queimadores, no fundo da quadra. Os alunos correm para fugir de Laís e Jeferson. Eles se aproximam de Jane, ela não dificulta para que a dupla a queime. Assim, ela se integra ao grupo, formando um trio. Prosseguem o jogo passando a bola entre eles, em direção aos outros jogadores. Ítalo movimenta-se sem dificuldades pelo espaço, porém de forma mais lenta em relação aos demais, para escapar da queimada. 0 trio conquista mais um integrante, e a movimentação da bola entre eles fica mais dinâmica, dificultando para os alunos que fogem. 0 grupo de queimadores estreita 0 espaço de movimentação de Ítalo, que, não conseguindo se livrar da bola, é queimado pela Laís. Agora no grupo, ele reinicia o jogo, passando a bola para a professora Jane, ela passa para Jeferson, que arrisca um arremesso no alvo, ou seja, em algum dos jogadores fugitivos. Não acerta, a bola fica para Laís, ela passa para Jane, que procura por Ítalo, meio distante, e realiza um lançamento longo da bola, acionando-o. Ele recepciona bem a bola, passa para o colega, que a devolve. Ítalo fica em boa situação para queimar alguém, arremessa e obtém sucesso. Agora com mais um, continuam o jogo. Porém, não conseguem estabelecer o dinamismo anterior na troca de passes. A bola fica muito tempo entre dois jogadores, infringem a regra com mais frequência, andando e segurando a bola. Jane intervém, pede tempo para reunir o grupo. Conversa com os alunos do grupo de queimadores sobre o jogo. Voltam para o jogo, conseguem queimar mais colegas. 0 grupo vai ficando maior, e a bola fica cada vez mais restrita a poucos integrantes. Ítalo quase não recebe mais a bola, e quando tem acesso, é por um passe vindo da professora Jane. Restam poucos para serem queimados, e logo o jogo termina. Jane disponibiliza cinco minutos para os alunos tomarem água e retornarem à aula. Todos vão $\mathrm{e}$ voltam logo, ela propõe para jogarem novamente, escolhe dois novos alunos para iniciar, e dessa vez não participa. Na segunda vez, o jogo tem a mesma característica de organização, porém, Ítalo não é queimado. Lê muito bem a movimentação do grupo queimador; desse modo, vai ocupando espaços opostos.

O episódio tem início com a professora Jane apresentando aos alunos a bola de handebol e seus diferentes tamanhos (turno 1). Em seguida, propõe uma atividade para trabalhar habilidades necessárias para se jogar handebol (turno 2). Ela os orienta sobre tais habilidades, sobre as regras da atividade e objetivo do jogo (turnos 2, 3 e 6). Nesses momentos, Ítalo participa das explicações, com os demais colegas. A deficiência física do aluno parece não ser um motivo de restrição para sua participação na atividade.

Retomam-se as contribuições de Vigotski $(1995,2000)$ sobre a natureza social do desenvolvimento humano e o papel fundamental das relações intersubjetivas no processo de aprendizagem. É por meio da mediação semiótica e dos instrumentos técnico-semióticos (DAINEZ; DECIETE, 2012) que o sujeito, na relação com o outro, vai elaborando os conceitos escolares (sistematizados). No episódio, os atos educativos da professora são intencionais: ela nomeia os tipos de bola, explica as habilidades, orienta quanto às regras do jogo, explicita 0 objetivo; enfim, são variados os modos de ensinar da professora Jane, todos eles permeados 
por palavras e gestos e, desse modo, ela vai envolvendo os alunos e eles participam da tarefa proposta.

Ressalta-se, nesse processo, o papel do outro como fator preponderante na constituição da subjetividade humana. Na escola, a principal referência para o aluno é o professor. Nessa direção, percebe-se que, na primeira rodada do jogo (turno 23), é sua professora quem oportuniza a Ítalo condições de manusear o instrumento bola, elemento de mediação externa nessa atividade, o qual provoca operações mentais. Conforme Smolka (2004, p. 43), "[...] somente na relação com o outro torna-se corpo significativo, corpo que sente e pensa, corpo tornando signo, corpo com estatuto de sujeito, que se vê, se (re)conhece. Corpo marcado, afetado pelas práticas historicamente construídas [...]".

As ações educativas da professora possibilitam que Ítalo experimente e manipule a bola, como também vivencie situações de sucesso ou fracasso durante a atividade: ele é queimado, recomeça, recepciona a bola adequadamente e percebe a movimentação do jogo.

Nesse episódio, constata-se uma situação diferente da que foi apresentada por Souza e Smolka (2009), sobre o modo como um aluno com deficiência é significado pelo seu professor e recebe um tratamento diferenciado, com poucas expectativas; o que destaca suas fragilidades em relação aos demais alunos. Diferente, também, dos dados revelados na pesquisa de Chicon, Mendes e Sá (2011), que identificaram atitudes de segregação de alunos com necessidades educacionais especiais por parte dos pares, devido à naturalização da não participação desses alunos durante as aulas.

\section{Episódio 3:}

A professora Marisa apresenta a tarefa que irão desenvolver. Consiste da atividade: caminhada e corrida. Os alunos devem caminhar em volta da quadra, alterando o ritmo do movimento conforme o comando da professora. Desse modo, ela solicita que os alunos levantem e iniciem o exercício. Guiado pela aluna Ana João, aluno cego, coloca a mão direita no ombro esquerdo de Ana, e começam a atividade como os demais alunos:

1. Profa.: Vamos lá, pessoal, vocês vão caminhar em volta da quadra no ritmo de vocês.

2. João: Aquecimento, aquecimento galera.

3. Ana: Pode ir?

4. João: Pode ir. (Começa a caminhar guiado por Ana)

5. Vinícius: Vou cortar por aqui. (Encurta o caminho a ser percorrido)

6. João: Professora quer que eu corte pelo meio da quadra e dou um gás ai? (A professora não ouve)

7. Ana: Não vai cortar nada.

8. Bruna: Já está cansado, João?

9. João: Eu estou tranquilo, só vocês que estão andando aí ó.

10. Profa.: Por favor, passem pelo lado de fora da quadra.

11. Ana: Escutou, João? Sem cortar caminho.

12. João: Não quero cortar, estou tranquilo, dá até para correr.

13. Profa.: Vamos acelerar um pouquinho.

14. Vinícius: Vou acelerar. (Na frente e ditando o ritmo, começa a trotar) 
15. João: Aquecimento.

16. Bruna: Meu físico está ruim.

17. João: Acelera.

18. Ana: Sua mão está pesada. (A mão de João sobre o ombro de Ana)

19. João: Vou colocar menos peso.

20. Vinícius: (Na frente, aumenta o ritmo da corrida, alguns alunos cansam e começam a caminhar)

21. João: Está vendo, não pode judiar de vocês. (Sorri, acompanha o ritmo de Vinícius guiado por Ana, sem apresentar cansaço)

22. Ana: Ah, João, você corre todo dia.

23. João: Quantas voltas assim, professora, trinta eu faço tranquilo. (Correndo)

24. Profa.: Calma, João [...].

25. Ana: Não é certo eu correr com o João, professora, o passo dele dá dois do meu.

26. Profa.: (Sorri)

27. João: É só você treinar.

Nesse fragmento ressalta-se o modo como a professora Marisa organizou a atividade, permitindo que Ana, colega de João, auxiliasse na tarefa. A professora, além de orientar os alunos sobre a atividade, disponibiliza uma estratégia para que João possa realizar o exercício proposto: 0 aluno guia. Seu histórico de motricidade humana e o condicionamento adquirido pelas práticas de corrida ${ }^{4}$ permitiram-lhe realizar a atividade sem dificuldades. Porém, mesmo com essa condição orgânica, João não teria participado sem a presença do outro.

Vigotski (2000) esclarece sobre a importância do "Outro" na constituição humana, durante as tensões e tramas das relações, seja nas atitudes solidárias e cooperativas, seja nas relações que geram conflitos. Para o autor, o homem é um conjunto de relações sociais, considerado um ser não apenas biológico, mas cultural. $O$ fato de João ser cego não o impede de participar das atividades físicas, pois o biológico não é determinante do desenvolvimento, mas, sim, as possibilidades oferecidas pelo meio sociocultural.

Dainez (2009), sobre a noção de compensação na perspectiva histórico-cultural, ressalta que o sujeito é dependente das condições concretas que são oferecidas pelo grupo social para uma participação qualitativa nas práticas sociais. Assim, no contexto escolar, as práticas educativas serão organizadas em decorrência do modo como a deficiência é concebida: focalizando apenas as limitações orgânicas, ou compreendida pela via das possibilidades. No episódio apresentado, a professora Marisa possibilita que João seja respaldado para que execute a tarefa. Durante a realização da atividade, ela o orienta sobre o percurso (turno 10), determina a alteração do ritmo (turno 13), e cria condições para que João realize a atividade, tendo a aluna Ana como guia.

Falkenback e Lopes (2010) observaram a participação de um aluno do ensino fundamental com deficiência visual nas aulas de Educação Física. Nas situações apresentadas, o aluno quase não participava das atividades, interagia pouco com os colegas da sua turma, os quais hesitavam em considerá-lo nas tarefas. 0 garoto manifestava implicitamente não

$\overline{4 \text { João é atleta paralímpico. }}$ 
gostar das práticas de Educação Física, embora houvesse um esforço do professor em promover situações propícias à participação do aluno. Nesse episódio, entretanto, encontrase um panorama diferente, uma vez que João participou ativa e interativamente da atividade promovida por sua professora, cuja atuação intencional foi determinante nesse processo, ao oportunizar condições para João desenvolver a tarefa com os seus pares.

\section{CONSIDERAÇÕES FINAIS}

Este estudo teve 0 intuito de analisar os modos de agir de professores de Educação Física na inclusão de alunos com deficiência na escola regular. Foram analisadas situações nas quais ocorreram as dinâmicas das aulas dessa disciplina, em que se procurou focalizar minúcias das relações intersubjetivas de duas professoras com seus alunos.

Nos episódios selecionados ressaltam-se as práticas de ensino das professoras, que viabilizaram condições favoráveis à participação dos alunos com deficiência durante as aulas. Condições essas orientadas pela mediação sígnica, ou seja, pelos modos de ação das professoras: elas convocam os alunos a realizarem as atividades, orientam, explicam, demonstram e, assim, pelas relações intersubjetivas, os conteúdos trabalhados vão se tornando significativos para os alunos com deficiência e esses realizam as tarefas, tendo, como os demais, possibilidades de aprendizagem na escola regular.

Infere-se que ações pedagógicas que visem à elaboração de conhecimentos escolares por alunos com deficiência são possíveis de ocorrer quando tais alunos são compreendidos pela via das possibilidades socioculturais, e não, somente, pelo olhar biológico, que naturaliza e limita tanto as ações dos professores para ensinarem, como as oportunidades para os alunos aprenderem.

A partir dessas constatações é possível tecer reflexões sobre a função da escola no ensino e na aprendizagem de todos os alunos. Alunos com deficiência, como os demais, estão na escola para aprender conteúdos sistematizados, científicos (SAVIANI, 1984; MARTINS, 2013). Para isso, as condições de ensino precisam estar a serviço do desenvolvimento dos alunos e pressupõem planejamento deliberado de ações didáticas para se trabalhar os conteúdos, que devem ser significativos aos alunos.

Nesse sentido, os currículos devem ser tomados como construção social (SACRISTÁN, 2000) e considerar as condições concretas das escolas e as singularidades de seus alunos. Todavia, como apontam Cação ${ }^{5}$ e David e Lourencetti (2015), sob a orientação do sistema neoliberal, as políticas de educação do Estado de São Paulo vêm preconizando um conjunto de reformas educacionais e, dentre elas, uma reorganização curricular, materializada na padronização do trabalho do professor, que deixa de ter autonomia para elaborar suas aulas e escolher sobre o que e como ensinar. Assim, as professoras desta investigação, ainda que estejam buscando inserir os alunos com deficiência nas atividades realizadas, estão também imobilizadas em seu fazer pedagógico, na medida em que são executoras de projetos e planos presentes na proposta curricular paulista (SÃO PAULO, 2010).

Por fim, ressalta-se que o ensino, compreendido como prática significativa, configurase como elemento mediador na relação entre aprendizagem e desenvolvimento e, assim, 0 
professor tem papel precípuo na tarefa de viabilizar condições propícias para sua efetivação. Entretanto, neste texto, chama-se a atenção para a contradição entre tal função docente e o esvaziamento de suas ações didático-pedagógicas, na medida em que a organização do trabalho pedagógico da sala de aula e da escola está cada vez mais padronizada em função das políticas educacionais vigentes.

\section{REFERÊNCIAS}

BRASIL. Ministério da Educação. Secretaria da Educação Especial. Política nacional de educação especial na perspectiva da educação inclusiva. Brasília: MEC/SEESP, 2008. Disponível em: < http://peei.mec.gov.br/arquivos/politica nacional educacao especial.pdf >. Acesso em: 13 out. 2016.

CHICON, José Francisco; MENDES, Katiuscia Aparecida Moreira de Oliveira; SÁ, Maria das Graças Carvalho Silva de. Educação Física e inclusão: a experiência na Escola Azul. Movimento, v. 17, n. 4, p. 185-202, out/dez. 2011.

DAINEZ, Débora; DECIETE, Nilce. Práticas de leitura nas con(tra)dições da educação inclusiva. Revista Leitura: teoria e prática, n. 58, p. 854-863, jun. 2012. Suplemento.

DAINEZ, Débora. Constituição humana, deficiência e educação: problematizando o conceito de compensação na perspectiva histórico-cultural. 2014. 137f. - Tese (Doutorado) - Faculdade de Educação, Universidade Estadual de Campinas, Campinas, 2014. Disponível em: <http://www. bibliotecadigital.unicamp.br/document/?code=000927683 >. Acesso em: 2016 .

DAVID, Alessandra; LOURENCETTI, Gisela do Carmo. A política educacional paulista: o Programa Ler e Escrever. Comunicações, v. 22, n. 1, p. 53-65, 2015.

FALKENBACH, Atos Prinz; LOPES, Elaine Regina. Professores de Educação Física diante da inclusão de alunos com deficiência visual. Pensar a Prática, v. 13, n. 3, p. 1-18, set./dez. 2010.

GAIO, Roberta Cortez; DIAS, Tárcia Regina da Silveira. Escola inclusiva e a formação de educadores: reflexões sobre a realidade brasileira. Innovación Educativa, n. 21, p. 107-118, 2011.

GÓES, Maria Cecília Rafael de. A abordagem microgenética na matriz histórico-cultural: uma perspectiva para o estudo da constituição da subjetividade. Caderno Cedes, v. 20, n. 50, p. 21, 2000.

KASSAR, Mônica de Carvalho Magalhães. Educação especial na perspectiva da educação inclusiva: desafios da implantação de uma política nacional. Educar em Revista, n. 41, p. 61-79, jul./set. 2011.

MARTINS, Lígia Márcia. 0 desenvolvimento do psiquismo e a educação escolar: contribuições à luz da psicologia histórico-cultural e da pedagogia histórico-crítica. Campinas, SP: Autores Associados. 2013.

SACRISTÁN, J. Gimeno. 0 currículo: uma reflexão sobre a prática. 3. ed. Porto Alegre: Art Med, 2000.

SÃO PAULO. Secretaria de Educação. Currículo do Estado de São Paulo: linguagens, códigos, e suas tecnologias. São Paulo: SEE, 2010.

SAVIANI, Dermeval. Sobre a natureza e especificidade da educação. Em aberto, v. 3, n. 22, p. 1-6, jul./ago. 1984. 
SEABRA JÚNIOR, Luiz. Inclusão, necessidades especiais e educação física: considerações sobre a ação pedagógica no ambiente escolar. Dissertação (Mestrado) - Faculdade de Educação Física, Universidade de Campinas, Campinas, 2006. Disponível em: <http://www.bibliotecadigital.unicamp.br/ document/?code=vtls000379904>. Acesso em: 6 maio 2012.

SERON, Taiza Daniela; BARBOSA-RINALDI, leda Parra; TULESKI, Silvana Calvo. Apropriação dos conceitos de Lev Semenovitch Vigotski no âmbito das pesquisas em educação física. Movimento, v. 17, n. 2, p. 75-91, jul. 2011.

SILVA, Fabiano Pires da. A constituição do professor no contexto da educação inclusiva: reflexões sobre sua formação e prática. 2015. 95f. Dissertação (Mestrado em Educação) - Programa de Mestrado, Centro Universitário Moura Lacerda, Ribeirão Preto, 2015.

SMOLKA, Ana Luiza Bustamante. Sobre significação e sentido: uma contribuição à proposta de rede de significações. In: ROSSETTI-FERREIRA, Maria Clotide et al. (Org.). Rede de significações e o estudo do desenvolvimento humano. Porto Alegre: Artes Médicas, 2004. v. 1, p. 35-49.

SOUZA, Flavia Faissal de; SMOLKA, Ana Luiza Bustamante. Políticas de Educação Inclusiva: a escola como lugar de constituição de corpos/sujeitos com deficiências. In: CONGRESSO BRASILEIRO DE CIÊNCIAS DO ESPORTE, 16., CONGRESSO INTERNACIONAL DE CIÊNCIAS DO ESPORTE, 3., Salvador, 2009. Anais... Disponivel em:<http://congressos.cbce.org.br/index.php/ conbrace2009/XVI/paper/view/1379/653>. Acesso em: 22 nov. 2015.

VYGOTSKI, Lev Semenovitch. A construção do pensamento e da linguagem. 2. ed. São Paulo: Martins Fontes, 2009.

VYGOTSKI, Lev Semenovitch. Obras escogidas III: problemas del desarrollo de la psique. Madrid: Visor, 1995

VYGOTSKI, Lev Semenovitch. Obras escogidas V: fundamentos de defectologia. Madrid: Visor, 1997.

VYGOTSKI, Lev Semenovitch. Manuscrito de 1929. Educação e Sociedade, Campinas, v. 21, n. 71, p. 23-44, 2000. 
